\title{
Musicoterapia no processo de reabilitação de pacientes com amputação
}

\section{Music therapy in the reabilitation process with amputation patients}

Maristela Pires da Cruz Smith ${ }^{1}$, Vera Lucia Rodrigues Alves ${ }^{2}$

\section{RESUMO}

A visão de totalidade do homem - homem como ser social - sugere que as ações reabilitadoras, aplicadas a pacientes acometidos por síndromes que os incapacitam fisicamente - como amputações de membros do corpo - mostram-se eficazes resultando numa melhora, e mais rápida readaptação do sujeito, a novas formas de 'estar no mundo', mesmo vivenciando um estigma social de "pessoa diferente". No estudo em questão trabalhou-se com os pressupostos epistemológicos da Psicologia Social Crítica, que foram demonstrados por meio de técnicas da Musicoterapia, pois se esperava que a prática de sessões de musicoterapia poderia facilitar a expressão da música interna dos sujeitos, conteúdo este narrado por meio de palavras, que foram transformadas em palavras cantadas e, posteriormente, em canções compostas. A participação dos envolvidos no trabalho clínico foi conjunta, isto é, entre pesquisadores e cada um dos 5 pacientes participantes, atendidos individualmente, já que se tratou de uma pesquisaação-participativa. As análises de discurso das narrativas de histórias de vida, foram feitas com base nas categorias que fundamentam a Psicologia Social Crítica. Os registros foram feitos a partir de observações do comportamento sonoro-musical dos pacientes, aplicando-se o "Modelo de Registro de Reações Sonoro-Rítmico-Musicais, Corpóreo-Vocais e Comportamentais", tanto para o registro objetivo, quanto para as interpretações musicais subjetivas, tendo como referência teórica principal a 'identidade como metamorfose'.

Palavras-chave: Pessoas com Deficiência, Amputados, Ego, Musicoterapia

\begin{abstract}
${ }^{1}$ Setor de Musicoterapia, Serviço de Psicologia, Instituto de Medicina Física e Reabilitação HCFMUSP

${ }^{2}$ Serviço de Psicologia, Instituto de Medicina Física e Reabilitação HCFMUSP

\section{Correspondência}

Maristela Pires da Cruz Smith

E-mail: maristela.smith@hc.fm.usp.br

Submetido: 12 Dezembro 2017

Aceito: 23 Maio 2018

\section{Como Citar}

Smith MPC, Alves VLR. Musicoterapia no processo de reabilitação de pacientes com amputação. Acta Fisiatr. 2018;25(3):145-148.
\end{abstract}

DOI: 10.11606/issn.2317-0190.v25i3a162672

\begin{abstract}
The holistic view of man - man as a social being - suggests that rehabilitative actions, applied to patients with physical disablement - such as limbs amputation - evidence efficacy, resulting in improvement and faster readaptation of the person to new ways of "being part of the world", even when experiencing the social stigma of being a "different person". This study explored the epistemological presuppositions of the Critical Social Psychology, which were demonstrated through Music Therapy techniques. It was expected that the practice of Music therapy sessions could facilitate the expression of the subject's internal music, whose content was recorded by means of words, subsequently transformed into singing words and then into music composition. It embraced the joint participation of the persons involved in the clinical work, that is between the researcher (author of this project) and in each of the five patients, viewed individually, since it involved a participatory action research. The speech analysis of the narratives of the life stories was based on the categories that substantiated Critical Social Psychology. The recordings entered were based on patients' sonorous-musical behavior observations, applying the "Recording Model of Sonorous-Rhythmic-Musical, Body-Vocal and Behavioral Reactions", not only for the objective registration, but also for the subjective musical interpretations, with "the identity as metamorphosis" being the main theoretical reference.
\end{abstract}

Keywords: Disabled Persons, Amputees, Ego, Music Therapy 


\section{INTRODUÇÃO}

Pacheco e Alves ${ }^{1}$ referem que os indivíduos deveriam ter uma postura mais reflexiva com relação ao preconceito existente à pessoa com deficiência, posturas estas relativas à marginalização, ao assistencialismo, à educação, à reabilitação, à integração e à inclusão social, pois, quando o processo de reabilitação está baseado no paradigma da inclusão, este poderá trazer maior possibilidade para que o indivíduo reflita sobre os valores que a cultura pode ter com relação à deficiência e, assim, se torne um agente de mudança no contexto social.

Em 2016 foi realizada pesquisa no Instituto de Medicina Física e Reabilitação do Hospital das Clínicas - IMREA HCFMUSP, onde se trabalhou com os pressupostos epistemológicos da Psicologia Social Crítica, demonstrados por meio de técnicas da Musicoterapia, pois se esperava que a prática de sessões de musicoterapia poderia facilitar a expressão da música interna dos sujeitos, conteúdo este narrado por meio de palavras, que foram transformadas em palavras cantadas e, posteriormente, em canções compostas. Tal pesquisa foi fruto do curso de doutorado em Psicologia Social da Pontifícia Universidade Católica de São Paulo - PUC/SP.

A participação dos envolvidos no trabalho clínico foi conjunta, isto é, entre os pesquisadores e cada paciente participante, atendido individualmente, já que se tratou de uma pesquisa-ação-participativa.

As análises de discurso das narrativas de histórias de vida, foram feitas com base nas categorias que fundamentam a Psicologia Social Crítica no estudo do homem: atividade, consciência e afetividade sendo que a categoria "identidade" comporta as três citadas - e interpretadas com uso de técnicas da Musicoterapia.

Os registros foram feitos a partir de observações do comportamento sonoro-musical dos pacientes, aplicando-se o "Modelo de Registro de Reações Sonoro-Rítmico-Musicais, CorpóreoVocais e Comportamentais", ${ }^{2}$ tanto para o registro objetivo, quanto para as interpretações musicais subjetivas, tendo como referência teórica principal a 'identidade como metamorfose', de Ciampa. ${ }^{3}$ Razão e emoção, tanto quanto "objetividade e subjetividade", não são dissociadas, o que corrobora a teoria que sustentou esta pesquisa, de caráter qualitativo.

Os cinco sujeitos foram submetidos a processos clínicos individuais em musicoterapia, na sala de Musicoterapia do IMREA, com a finalidade de levá-los a ressignificarem suas visões de mundo, a partir da aquisição de novas personagens do presente, somadas ao passado e com projetos de vida futuros e emancipatórios. $O$ estudo foi pautado em três pilares: 1) na identidade como metamorfose (psicologia social crítica); 2) na influência do uso de técnicas musicoterapêuticas (musicoterapia clínica) e; 3) na reabilitação de cinco pessoas com amputações adquiridas (área da saúde).

Trabalhar a identidade de pessoas com deficiência adquirida, que expressam suas emoções e sentimentos, por intermédio de letras de composições musicais próprias, quando são estimuladas, ao se transformarem em pessoas diferentes, reaprendem, na maioria das vezes, a adaptar-se a uma nova realidade, com novos valores, experimentando novas personagens, assumindo novos papeis até então desconhecidos por eles, ressignificando os sentidos de suas vidas e buscando fragmentos de emancipação.

Este é o objeto de estudo da Musicoterapia, voltada à pessoa com amputação. Assim, a identidade é vista como um processo natural e, no estudo realizado, evidenciaram-se identidades interrompidas num determinado momento, devido a fatos externos ocorridos, que transformaram vidas.

A identidade social abarcou as categorias do psiquismo humano, constituindo o cerne do trabalho. Entretanto, a prática da Musicoterapia foi a ferramenta terapêutica utilizada, como estratégia de abertura de canais de comunicação, ou seja, das expressões dos cinco pacientes, sujeitos da pesquisa.

O método de análise do discurso, de narrativas "sonoro-musicais" das histórias de vida, buscou extrair ou externalizar problemas e crenças. Numa narrativa podemos esperar que o sujeito conte e/ou cante sua história, tanto no sentido real, quanto no imaginário. Isso nos faz lembrar quando oferecemos a principal técnica utilizada em musicoterapia receptiva, a escuta, em que o paciente reage e relata o que sentiu, muitas vezes associando a música ouvida a eventos ocorridos em sua vida pregressa; outras vezes, cria cenas imaginárias.

\section{OBJETIVO}

O objetivo geral da pesquisa foi compreender o processo de metamorfose da identidade de cinco pessoas, que sofreram amputações, na fase adulta. $E$, para tanto, validou-se uma prática musicoterapêutica que possibilitou aos pacientes ressignificar suas existências.

\section{MÉTODOS}

A definição da World Federation of Music Therapy - Federação Mundial de Musicoterapia, ${ }^{4}$ nos parece a mais completa, pois abrange a disciplina como um todo e possibilita trabalhar em qualquer especificidade que seja. Padronizou-se que: Musicoterapia é a utilização da música e/ou de seus elementos (som, ritmo, melodia e harmonia), por um musicoterapeuta qualificado, com um cliente ou grupo, num processo para facilitar e promover a comunicação, relação, aprendizagem, mobilização, expressão, organização e outros objetivos terapêuticos relevantes, no sentido de alcançar necessidades físicas, emocionais, mentais, sociais e cognitivas.

Os procedimentos utilizados nas sessões musicoterapêuticas visaram conhecer a estrutura das músicas expressadas pelos sujeitos elaborando, a partir daí, uma análise sonoro-musical, o que levou a interpretações.

As etapas de um processo musicoterapêutico, seguindo-se a sistematização de $\mathrm{Smith}^{2}$ podem ser resumidas em: 1) etapa musicodiagnóstica; 2) etapa de desenvolvimento e; 3) etapa conclusiva. No método de "Ação Participativa", adotamos algumas técnicas, dentre elas: Na etapa musicodiagnóstica aplicou-se uma avaliação geral sonoro-musical, que inclui dois testes: um para memória operacional para ritmo e outro para memória operacional para melodia.

$\mathrm{Na}$ etapa de desenvolvimento, os potenciais rítmicos e melódicos dos pacientes foram trabalhados, com vistas ao alcance dos objetivos prescritos. Para tanto, técnicas musicoterapêuticas foram aplicadas, tais como:

- Aproximação

- Escuta Musical

- Improvisação (livre e orientada)

- Canção

- Construção sonoro-musical

- Projetivo-sonora

- Composição musical X composição assistida

- Audição Musical

- Relaxamento X aquecimento

- Recriação

- Provocativa-musical X Provocativa pré-musical

$\mathrm{Na}$ etapa conclusiva, as sessões foram dialogadas tornando conscientes as ações realizadas pelos pacientes, em conjunto com o musicoterapeuta.

A amostra abrangeu um universo de cinco pacientes. O tempo de entrevista não teve uma duração fechada (embora não tenha ultrapassado os 50 minutos), mesmo porque, cada paciente demonstrou seu ritmo de exposição e isso teve que ser respeitado. Ao todo, foram realizadas 50 sessões de Musicoteraipa (10 para cada paciente) e a consigna inicial, no início de cada entrevista, foi: "Fale sobre você".

Por se tratar de uma pesquisa em que envolveu seres humanos, seguiu-se os princípios regidos na Declaração de Helsinki, dando-se ênfase à mudança ocorrida no ano de 2000 , em que foi inserido o 
Artigo 19, introduzindo-se o conceito de justiça social, estendida aos indivíduos da comunidade como um todo. A mesma afirma que "a investigação só se justifica se houver uma probabilidade razoável de que as populações nas quais a pesquisa é realizada se beneficiar dos resultados da investigação". E isso ocorreu nesta pesquisa, visto que todo o grupo de pessoas com deficiências poderá fazer uso do método empregado.

\section{RESULTADOS}

Optou-se por apresentar cada pessoa, individualmente, sintetizando-se as palavras, ou frases expressadas no início do processo de 10 sessões, com duração de 45 a 50 minutos cada e as palavras cantadas ao término das mesmas, denotando-se momentos de ressignificação, demonstrados não-verbalmente, ou relatados pelos indivíduos.

Quadro 1. Sujeitos denominados por codinomes e suas falas no início e término do processo

\begin{tabular}{|c|c|}
\hline \multicolumn{2}{|c|}{ Sujeito 1: Riqueza de Sonoridades } \\
\hline $\begin{array}{l}\text { No início do processo } \\
\text { musicoterápico }\end{array}$ & $\begin{array}{l}\text { Ao término do processo } \\
\text { musicoterápico }\end{array}$ \\
\hline Difíil & Tentativa \\
\hline $\begin{array}{l}\text { Respeito (negando-se a manipular } \\
\text { ou explorar os instrumentos } \\
\text { musicais }\end{array}$ & $\begin{array}{l}\text { Exploração dos instrumentos } \\
\text { musicais dispostos no setting }\end{array}$ \\
\hline Luto & Vida, superação \\
\hline Velho (com relação à própria idade) & Modernidade; soltura \\
\hline Medo & Enfrentamento \\
\hline \multicolumn{2}{|c|}{ Sujeito 2: Violão e Amigos } \\
\hline $\begin{array}{l}\text { No início do processo } \\
\text { musicoterápico }\end{array}$ & $\begin{array}{l}\text { Ao término do processo } \\
\text { musicoterápico }\end{array}$ \\
\hline Fim do tempo & Nova História \\
\hline Sem amigos, sem história & Volta dos amigos \\
\hline Desilusão & Sonho possivel \\
\hline Dependente & Dono do meu nariz \\
\hline Não sei mais nada & Vi que sou capaz \\
\hline \multicolumn{2}{|c|}{ Sujeito 3: Nostalgia em Sol Maior } \\
\hline $\begin{array}{l}\text { No início do processo } \\
\text { musicoterápico }\end{array}$ & $\begin{array}{c}\text { Ao término do processo } \\
\text { musicoterápico }\end{array}$ \\
\hline Sentimentos guardados & Consegui contar, cantando \\
\hline É melhor nem tentar & Até que sou bom nisso \\
\hline Fazer música é impossível & Sou compositor, finalmente \\
\hline \multicolumn{2}{|c|}{ Sujeito 4: As Palmeiras do Palmeiras } \\
\hline $\begin{array}{l}\text { No início do processo } \\
\text { musicoterápico }\end{array}$ & $\begin{array}{l}\text { Ao término do processo } \\
\text { musicoterápico }\end{array}$ \\
\hline Não dá mais & Vou continuar cantando em casa \\
\hline Minha voz é feia; sou péssimo nisso & Cantei afinado \\
\hline Saudades de mim & Eu estou aqui \\
\hline $\begin{array}{l}\text { Que pena! (com relação à sua } \\
\text { condição física) }\end{array}$ & $\begin{array}{l}\text { Faço e refaço. Não sou menos que } \\
\text { ninguém }\end{array}$ \\
\hline \multicolumn{2}{|c|}{ Sujeito 5: O Velho Acordeão } \\
\hline $\begin{array}{l}\text { No início do processo } \\
\text { musicoterápico }\end{array}$ & $\begin{array}{l}\text { Ao término do processo } \\
\text { musicoterápico }\end{array}$ \\
\hline Sou um imbecil & Me olho no espelho e gosto de mim \\
\hline $\begin{array}{l}\text { Será que poderei ser um } \\
\text { compositor? }\end{array}$ & $\begin{array}{l}\text { Crio composições até no } \\
\text { guardanapo do restaurante }\end{array}$ \\
\hline Minha mulher me odeia & $\begin{array}{l}\text { Sou companheiro e ela, } \\
\text { companheira }\end{array}$ \\
\hline $\begin{array}{l}\text { Já estou velho pra isso (com } \\
\text { relação a compor músicas) }\end{array}$ & $\begin{array}{l}\text { É muito gostoso pra gente, falar } \\
\text { cantando. Às vezes é engraçado! }\end{array}$ \\
\hline
\end{tabular}

\section{DISCUSSÃO}

Nesta pesquisa teórico-prática, procuramos enfatizar as histórias de experiências pessoais/musicais, analisadas sob a categoria-síntese "identidade", por meio de estratégias da Musicoterapia; em outras palavras, fez-se uso metodológico do instrumento "música como terapia", cantada em verso e prosa. Abordou-se, pois, o estudo de cinco casos, que foram relatados descritivamente, interpretados sob a ótica da Psicologia Social e analisados no âmbito musicoterapêutico.

As significações foram expressadas por meio de relatos verbais e expressões não-verbais dos próprios pacientes, que foram categorizadas por fases de suas vidas, o que caracterizou a ação participativa da pesquisa. Procurou-se manter o foco na captação dos significados.

Nossa meta foi atingir o indivíduo concreto, manifestação de uma totalidade histórico-social. Para isso, partimos do empírico e, por meio de análises sucessivas, nos aprofundamos na compreensão do seu conteúdo, que foi além do aparente, em direção a esse concreto. Essas análises foram feitas por meio das categorias do psiquismo humano, tais como o pensamento, a atividade, a consciência e a emoção, que são condensadas na Identidade Social Crítica, com foco no sintagma "identidade-metamorfose-emancipação", conceito básico para a Psicologia Social, desenvolvido por Ciampa, ${ }^{5}$ pois considera o indivíduo como um todo e, o mais importante, considera o indivíduo como um todo na sua relação com os outros indivíduos. O tipo de pesquisa foi caracterizado como "Pesquisa ação-participativa" e, como tal, pôde-se estabelecer um rapport, um laço forte com os sujeitos pesquisados, formando um ótimo canal de comunicação.

Utilizamos palavras e frases, que foram transformadas em voz cantada, verbalizadas sem intenção inicial, mas que contavam sobre rotinas de vida. A ponte que surgiu daí, levou os pacientes ao canto propriamente dito de frases sobre as rotinas de suas vidas presentes, passadas e de seus projetos futuros.

Em outras palavras, ao se propor este tipo de pesquisa, entramos num olhar e numa escuta dupla, pois, nos deparamos com a palavra e com a música, ao mesmo tempo, para compreendermos como se dá a narrativa oral facilitada pela expressão sonoro-musical. Entendemos esse procedimento como uma técnica e foi a técnica da análise dupla, isto é, da palavra e da música, que definiu as categorias.

A pesquisa apresentou as análises como interesse das diferentes personagens que foram sendo criadas, ou que foram impedidas de se realizar, evidenciando-se as metamorfoses e os movimentos de emancipação, sempre a partir das autodeterminações. Em alguns casos, o presente foi reinventado; em outros, encontramos o fenômeno de alterização da identidade, ou seja, a superação das personagens pressupostas.

Aos momentos de grandes transformações qualitativas, chamamos "alterização da identidade", que, de acordo com Ciampa ${ }^{5}$ consiste na negação da negação que permite a expressão do outro "outro", que também sou eu. A frequência com que grandes mudanças foram percebidas, isto é, com grandes significados e sentidos pelos pacientes, promoveu-se um salto, gerado quantitativamente (número de vezes acontecida), mas, isso não significa que esse salto foi mecânico; pelo contrário.

Kolyniak $^{6}$ afirma que escapar da reposição e buscar o outro "outro" é superação, é metamorfose emancipatória, é negação da negação. Isto permite com que se represente um novo eu, diferente da identidade pressuposta e também que se transformem as formas de desempenhar papeis, além do que se deixe de repor, para passar a superar as velhas representações.

Assim, a música expressada, cujos significados podem se assemelhar, mas cujos sentidos são particulares e dependem, em grande parte, das histórias de vida e do quanto eventos dessas histórias são relevantes para mais ou para menos, em cada pessoa, serviu de material interpretado. As narrativas "contadas" em palavras foram transformadas em narrativas "cantadas", nas formas melódica, rítmica e harmônica.

\section{CONCLUSÃO}

Analisamos cada sujeito de pesquisa, que passou pelo processo breve de musicoterapia, totalizando em torno de 10 sessões, de 45 a 50 minutos cada. Entretanto, registramos as entrevistas, ou os 
primeiros encontros e, resumimos as sessões de cada paciente, condensando as principais atividades e conclusões feitas em conjunto. Elegemos codinomes, representando o sentimento e o pensamento manifestos, bem como as ações que interpretamos como de maior relevância.

Os registros das composições em si, foram feitos de acordo com o entendimento da pesquisadora, que se baseou nos ensinamentos de Murray Schafer ${ }^{7}$ e também na realidade dos pacientes e da instituição.

Optou-se por desenvolver uma prática que viesse facilitar a expressão verbal dos sujeitos participantes, com o fim de aproximar as duas formas de conhecimentos, levando-se em consideração que a musicoterapia, como técnica de mediação, pudesse servir de auxiliar na abertura de canais de comunicação e também como facilitadora de transformação, referente ao estudo da identidade como metamorfose de pessoas amputadas.

O fundamento teórico principal desta pesquisa foi o sintagma "identidade-metamorfose-emancipação", de Antônio da Costa Ciampa, ainda em construção, porém, o aspecto musical dos sujeitos como algo presente em suas vidas, colaborou para a ideia da totalidade do ser humano e facilitou a leitura, a análise e a interpretação.

Além disso, como uma contribuição à responsabilidade social, quisemos demonstrar de que forma sujeitos traumatizados por amputações conseguem ressignificar suas vidas, diante de novas personagens, assumindo novos papeis e redescobrindo que poderão expressar seus sentimentos e rotinas de vida, por meio do lirismo popular, transformando simples palavras da rotina de suas vidas, que viraram textos escritos, em composições musicais, o que acarretou no aumento do grau de autoestima e consequente autoimagem de cada paciente.

Nosso foco não se abrigou na produção em si, mas, sim, na contribuição que pudemos dar para compreendermos melhor o comportamento desses sujeitos. Seguindo o pensamento de Ciampa ${ }^{5}$ em que a identidade é um processo de metamorfose permanente envolvendo diferentes momentos, os pacientes aqui estudados foram apresentados após terem sofrido amputações. Desta forma, suas metamorfoses foram afetadas de forma significativa, ou seja, podemos pensar que o passado (história de vida pregressa) serviu de aprendizado e que o futuro (projetos e ideais de vida) foi ressignificado e transformado, através de novas ações, no presente.

Entretanto, isso não quer dizer que esse novo sentido teria que ser, necessariamente negativo, estereotipado ou estigmatizado. Entendemos que as "descobertas" acenderam novas perspectivas. Sabemos que uma pessoa amputada pode perfeitamente continuar sua existência com qualidade de vida. Com base nesta afirmação, o encaminhamento dos pacientes à musicoterapia se deu, para que os mesmos pudessem vir a experimentar novas formas de pensar e sentir a vida, ressignificando valores, metamorfoseando metamorfoses.

Ao final do breve processo musicoterapêutico, os pacientes relataram ser o tempo de participação insuficiente. Dois deles se dispuseram, por livre e espontânea vontade, a compor em casa e a trazer letras sobre suas rotinas de vida, o que foi permitido, pois a pesquisadora entendeu que $o$ ato criativo poderia se dar em outras situações e ambientes diversos.

O uso do registro de reações sonoro-rítmico-musicais, corpóreovocais e comportamentais proporcionou, no trabalho de Musicoterapia, uma visão global dos pacientes atendidos e consequentes análises tanto quantitativas, como qualitativas, dirigindo melhor a sequência do processo terapêutico.

Houve participação no mundo intersubjetivo; as mudanças ocorridas ao longo do processo musicoterapêutico facilitaram encontrar intersecções entre as duas áreas: Psicologia Social e Musicoterapia, apesar de este não ter sido o objetivo do trabalho.

Concordamos com Bartolini ${ }^{8}$ quando diz que o que vale de uma leitura é o conhecimento novo produzido a partir do encontro daquelas ideias com as experiências pessoais do leitor. Assevera ele: é como numa leitura de partitura: o músico que se configura um mero reprodutor de notas, ou seja, daquilo que está lendo, permanece no nível léxico do texto, enquanto aquele que imbui de compreensão pessoal a sua interpretação, produz um conhecimento novo a partir da leitura.

$\mathrm{Na}$ verdade, todos nós aprendemos juntos e este foi o maior trunfo, do qual nos orgulhamos. Entende-se que a contribuição deste trabalho foi ter propiciado aos sujeitos de pesquisa novas escolhas e planejamento de seus próprios futuros, contemplando a meta de contribuir para um compromisso social de maior qualidade e amplitude. Quiçá possamos dar continuidade a esta investigação, aumentando o número de pessoas participantes e contribuindo para tornar o "mundo da vida" mais feliz!

\section{AGRADECIMENTOS}

Agradecemos à PUC/SP, curso de doutorado em Psicologia Social, especialmente ao Professor, orientador deste trabalho, Dr. Antonio da Costa Ciampa, bem como ao Instituto de Medicina e Reabilitação IMREA HCFMUSP - Rede Lucy Montoro, por ter proporcionado condições adequadas para a realização da parte técnico-prática.

Agradecemos também aos pacientes do IMREA, pertencentes ao programa de reabilitação por terem aceitado ser sujeitos da pesquisa.

\section{REFERENCIAS}

1. Pacheco KMB, Alves VLR. A história da deficiência, da marginalização à inclusão social: uma mudança de paradigma. Acta Fisiatr. 2007;14(4):242-8.

2. Smith MPC. Musicoterapia e identidade humana: transformar para ressignificar. São Paulo: Memnon; 2015.

3. Ciampa AC. A identidade social e suas relações com a ideologia [Dissertação]. São Paulo: Pontifícia Universidade Católica de São Paulo;1977.

4. Definição de musicoterapia. Rev Bras Musicoter. 1996;1(2):4.

5. Ciampa AC. Objeto da psicologia: ética e pesquisa. In: Conselho Regional de Psicologia. Práticas alternativas: campo da psicologia. São Paulo: Express; 1998.

6. Kolyniak HMR. Identidade e corporeidade: prolegômenos para uma abordagem psicossocial [Tese] São Paulo: Pontifícia Universidade Católica de São Paulo; 2002.

7. Schafer M. O ouvido pensante. São Paulo: UNESP; 1991.

8. Bertolini I. Como a Educação Musical ajuda no aprendizado de leitura e escrita? [texto na Internet]. São Paulo: Abril [citado 2016 Set 30]. Disponível em: http://www.educarparacrescer.abril.com.br/aprendizagem/com o-educacao-musical-ajuda-aprendiz 